\title{
The critical period of reservoir systems considering performance indices on Malaysia rivers
}

\author{
Issa Saket Oskoui ${ }^{1}$, Rozi Abdullah $^{1}{ }^{*}$, Majid Montaseri $^{2}$ \\ ${ }^{1}$ School of Civil Engineering, University Sains Malaysia, 14300 Nibong Tebal, Penang, Malaysia \\ ${ }^{2}$ Department of Water Engineering, Urmia University, Urmia, Iran \\ *Corresponding author E-mail: cerozi@usm.my
}

Copyright $\odot 2014$ Issa Saket Oskoui et al. This is an open access article distributed under the Creative Commons Attribution License, which permits unrestricted use, distribution, and reproduction in any medium, provided the original work is properly cited.

\begin{abstract}
The behavior of reservoir systems can be investigated using Critical Period (CP) which determines the aggregation level of the data (monthly or annual) that are required to be utilized in the reservoir analysis. Currently there are a number of methods that could approximate the behavior of reservoir systems, however the efficiency of these approaches have not been studied and verified for the Malaysia Rivers. In this study two different hypothetical reservoirs on Malaysia Rivers are selected. The stream flow data are subjected to preliminary analysis and evaluation of the fittest probability distribution function. Afterwards, the $\mathrm{CP}$ is estimated by applying a Monte Carlo simulation technique and considering performance indices. The $\mathrm{CP}$ from this study is used to determine the within-year or over-year behavior and these results are compared with those of the previous well-known equations in this area. It is observed that existing equations are incomplete and other parameters such as reliability and vulnerability should be considered to predict the behavior of reservoir systems. Consequently two separate regression equations are proposed to estimate the $\mathrm{CP}$ of these reservoir systems in Malaysia and some suggestions are made to generalize and extend this study.
\end{abstract}

Keywords: Critical Period, Monte Carlo Simulation, Over-Year Behavior, Performance Indices, Reliability, Vulnerability, Within-Year Behavior.

\section{Introduction}

The analysis and simulation of a reservoir system is usually carried out using historical data, however it is unlikely that reservoir is subjected to the similar sequence of data in the future and droughts might occur in future that are more severe than historical ones [1]. Thus for a realistic analysis of reservoir systems, appropriate synthetic stream flow data generation techniques have been implemented that are widely used especially in developed countries [2], [3], [4].

The analysis of reservoirs is traditionally performed using techniques that involve time based reliability of $100 \%$. However designing reservoir systems which are enormous facilities with $100 \%$ reliability is not economical. Moreover there are some periods in reservoir operation that due to unexpected demand pattern changes or droughts it is not possible to provide all the target demand. These periods are called failure periods. Hence, acceptance of failure period as a reality in designing stage of reservoirs is necessary and the involvement of performance indices such as reliability and vulnerability to control the performance of reservoirs during this period is desirable [5], [6], [7]. Reliability represents the time based probability in which reservoir can provide all the design demand and vulnerability exhibits the severity of failure [8], [9]. For instance reliability of $98 \%$ indicates the reservoir is able to provide all the design demand in $98 \%$ of the operational period and the vulnerability of $30 \%$ indicates the reservoir may not be able to provide $30 \%$ of the target demand during the failure period and it is necessary to find an alternative water resource during this period. Analysis of reservoir systems could be carried out by applying two general methods. First one is called probability matrix method which is developed in Australia and is based on direct modeling of reservoirs [10], [11]. The second approach is termed as critical period approach that is categorized under simulation and optimization classes [12]. Among the two methods, simulation approaches have enough flexibility to involve performance indices in the analysis. Therefore modified Sequent Peak Algorithm (SPA) that belongs to the simulation class is used in this study. In this approach it is feasible to involve both reliability and vulnerability indices in the analysis. 
Critical Period (CP) is defined as a time when a full reservoir goes empty without spilling in the intervening period [13], however it differs from the North American definition which describes critical period as a time that is required for a full reservoir to become empty and then full again [14]. In this study the former definition of critical period is adopted and its North American equivalent is critical drawdown period [15].

$\mathrm{CP}$ is applied to determine two important behavior types of reservoir systems. The behavior that is related to having critical period less than one year is called within-year and the one that is involved with critical period more than one year is termed over-year. These behaviors play a special role in understanding some important characteristics of reservoir systems such as storage capacity, reliability, vulnerability, resilience and sustainability [16]. Moreover it can be used to distinguish the appropriate aggregation of stream flow data (monthly or annual) that is required prior to perform the reservoir system analysis. For example if reservoir shows within-year behavior it is required to use twelve critical monthly flows in the analysis whereas if reservoir exhibits over-year behavior annual stream flow will be sufficient.

Well-known criteria that are used to determine the behavior of reservoir systems is standardized demand parameter (m) that is defined as follows:

$\mathrm{m}=\frac{1-\alpha}{\mathrm{C}_{\mathrm{V}}}$

Where $\alpha$ is the demand as a percentage of river's Mean Annual Flow (MAF), $\mathrm{C}_{\mathrm{V}}$ denotes coefficient of variation of annual flow that is defined as standard deviation of annual flows divided by Mean Annual Flow (MAF). According to this approach if $\mathrm{m}>1$ the reservoir's behavior will be within-year and if $\mathrm{m}<1$ its behavior will be over-year. And $\mathrm{m}=$ 1 shows a transitional state between these two kinds of behaviors [17].

Afterwards, parameter m method was amended by including the coefficient of variation of annual flows, $\mathrm{C}_{\mathrm{V}}$; so overyear systems will have $\mathrm{C}_{\mathrm{V}}>1$ ( or $\mathrm{C}_{\mathrm{V}}<1$ and $0 \leq \mathrm{m} \leq \mathrm{C}_{\mathrm{V}}$ ) and within-year systems will have $\mathrm{C}_{\mathrm{V}}<1$ and $\mathrm{m}$ satisfying the inequality $\mathrm{C}_{\mathrm{V}} \leq \mathrm{m} \leq 1 / \mathrm{C}_{\mathrm{V}}$. The original and the modified parameter $\mathrm{m}$ methods were developed using some major reservoir data base in US [18].

However Montaseri and Adeloye (1999) showed that other than $\mathrm{m}$ and $\mathrm{C}_{\mathrm{V}}$ other parameters such as reliability and stream flow data length are important in the type of the behavior that reservoir systems would exhibit [16]. They developed regression equations to predict the $\mathrm{CP}$ of reservoir systems in England that is as follow:

$\mathrm{CP}=\left(-116.63+137.20 \mathrm{R}_{\mathrm{e}}+0.03 \mathrm{~L}_{\mathrm{e}}\right) \times \mathrm{m}^{\left(4.53-5.65 \mathrm{R}_{\mathrm{e}}-0.001 \mathrm{~L}_{\mathrm{e}}\right)}$

Where CP is critical period in months, $\mathrm{R}_{\mathrm{e}}$ is time based reliability between 0.9 and $1.0, \mathrm{~L}_{\mathrm{e}}$ is the length of stream flow data in years and $\mathrm{m}$ is standardized demand parameter (Equation 1). This equation is only calibrated for a few sites in England and may not be used elsewhere. Moreover other performance indices such as vulnerability are not considered in their study [16]. Thus, in this study after finding the CP by applying a Monte Carlo simulation approach in two hypothetical reservoirs of Malaysia new regression equations are developed to predict CP using both of reliability and vulnerability indices. As these two sites show different stream flow characteristics the equations are calibrated for each of them separately for obtaining high degree of accuracy.

\section{Methodology}

\subsection{Catchment study and stream flow data analysis}

The study is carried out on two Malaysian rivers. Firstly, Melaka is the driest catchment in Malaysia which receives less than $2000 \mathrm{~mm}$ of rainfall annually. However Melaka has never had a dry season because monthly average rainfall is more than $100 \mathrm{~mm}$. The second river catchment that is chosen for this study is Muar which receives about $2400 \mathrm{~mm}$ rainfall annually. Melaka and Muar both enjoy a year-round tropical rainforest equatorial climate which is warm, humid and sunny. The brief characteristics of river catchments are presented in Table 1.

Table 1: Characteristics and Locations of the River Catchments

\begin{tabular}{|c|c|c|c|c|c|c|c|c|c|}
\hline \multirow{3}{*}{ site } & \multirow{3}{*}{ River } & \multirow{3}{*}{ Gauging station } & \multirow{3}{*}{$\begin{array}{c}\text { Record length } \\
\text { (years) }\end{array}$} & Catchment & \multicolumn{5}{|c|}{ Annual flow statistics } \\
\hline & & & & Area & \multicolumn{2}{|c|}{ Mean } & \multirow{2}{*}{$\mathrm{C}_{\mathrm{V}}$} & \multirow{2}{*}{ Skew } & \multirow{2}{*}{$\rho^{*}$} \\
\hline & & & & $\left(\mathrm{Km}^{2}\right)$ & $(\mathrm{mm})$ & $\left(10^{6} \mathrm{~m}^{3}\right)$ & & & \\
\hline 1 & Melaka & Pantai Belimbing & $51(1962-2012)$ & 350 & 531 & 186 & 0.40 & 0.48 & 0.16 \\
\hline 2 & Muar & Buluh Kasap & 47 (1966-2012) & 3130 & 434 & 1359 & 0.48 & 2.03 & 0.18 \\
\hline
\end{tabular}

Primary data analyses have been carried out to ensure that stream flow data are of appropriate quality prior to time series analysis. This includes double mass diagram which shows that stream flow data for both sites are consistent and homogenous. Additionally, trend and run tests are applied on the data to make sure that data is stationary and it is the result of a random and natural process [19], [20]. Table 2 shows that test statistics for annual flows are within their allowable range and statistical hypothesizes that data are trend-free and random are valid. Finally the fittest probability 
distribution function for stream flow data is determined using Probability Plot Correlation Coefficient (PPCC) test [21]. Table 3 shows that annual stream flow of both rivers exhibits the highest correlation coefficients for Pearson III distribution which makes it proper to be used in modeling stream flow data for time series analysis. The fitness of Pearson III distribution function to historical annual stream flow data is also shown in Figure 1. For monthly stream flow data Pearson III is also the dominant distribution function.

Table 2: Distribution Free Test for Trend and Randomness of the Annual Flows at the 5\% Significance Level

\begin{tabular}{|l|l|l|l|l|}
\hline \multirow{4}{*}{ Site } & \multicolumn{2}{|c|}{ Trend } & \multicolumn{2}{c|}{ Randomness } \\
\cline { 2 - 5 } & Test & Critical value & Test & Critical value \\
\cline { 2 - 5 } & statistic & at 5\% level & statistic & at 5\% level \\
\cline { 2 - 5 } & & (t-distribution) & & (normal distribution) \\
\hline Melaka & -1.17 & \pm 2.02 & 0.72 & \pm 1.96 \\
\hline Muar & 0.09 & \pm 2.02 & -1.35 & \pm 1.96 \\
\hline
\end{tabular}

Table 3: Correlation Coefficients Obtained From the PPCC Test for Historical Annual Stream flow Data on the Study Catchments

\begin{tabular}{|c|c|c|c|c|c|}
\hline Site & Normal & Pearson III & LN2 & LN3 & LP III \\
\hline Melaka & 0.9865 & 0.9921 & 0.9796 & 0.9920 & 0.9863 \\
\hline Muar & 0.9055 & 0.9827 & 0.9717 & 0.9788 & 0.9826 \\
\hline
\end{tabular}

Note: The maximum PPCC for each site is underlined.
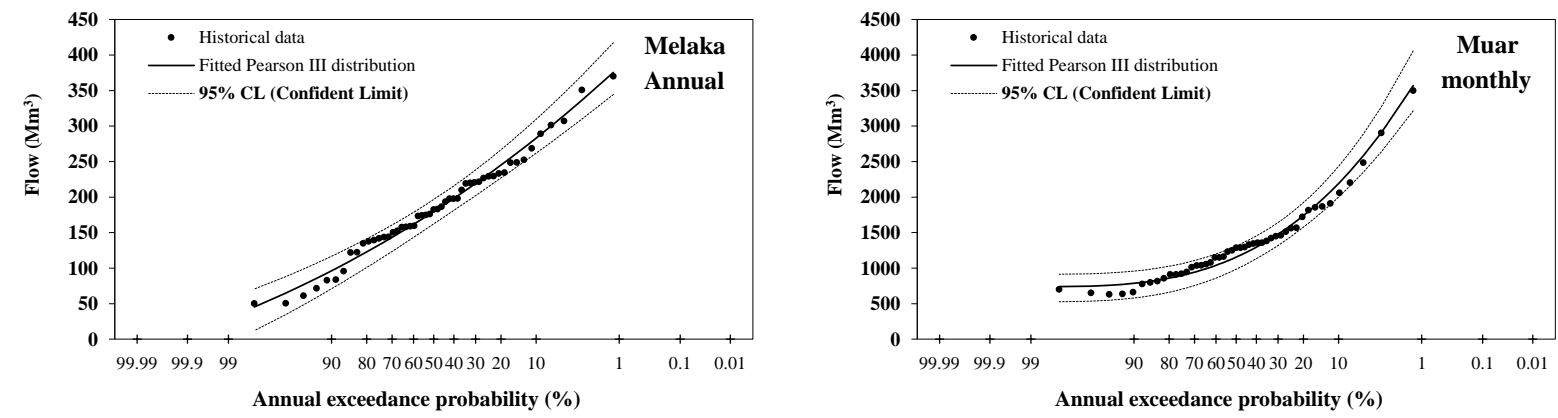

Fig. 1: Fitness of Pearson III Distribution Function to the Historical Annual Stream flow Data of Study Catchments

\subsection{Synthetic stream flow data generation}

Realistic analysis of reservoir systems should consider droughts that are more severe than historical ones. Hence data generation techniques are applied in this study [2]. Data generation models for reservoir system analysis must preserve the essential statistical characteristics of both annual and monthly historical stream flow data so the combination of Auto Regressive Lag one (AR (1)) to generate annual flows and Valencia and Schaake (V-S) to disaggregate annual flows to monthly flows are applied in this study rather than using a single model to generate monthly flows directly like Thomas-Fiering [22], [23]. The AR (1) model can be expressed by the following equation:

$\mathrm{q}_{\mathrm{i}+1}=\overline{\mathrm{q}}+\rho\left(\mathrm{q}_{\mathrm{i}}-\overline{\mathrm{q}}\right)+\mathrm{z}_{\mathrm{i}} \cdot \mathrm{s} \sqrt{1-\rho^{2}}$

Where $\mathrm{q}_{i+1}$ and $\mathrm{q}_{\mathrm{i}}$ are the annual flows for the (i+1) Th and ith years; $\overline{\mathrm{q}}$ is the mean of annual flows; $\mathrm{z}_{\mathrm{i}}$ is the standardized normal random variable; $\mathrm{s}$ is standard deviation and $\rho$ is lag-1 serial correlation of annual flows.

In Equation (3) the annual stream flow data are standardized and then normalized, so $\overline{\mathrm{q}}=0$ and $\mathrm{s}=1$. As the dominant probability distribution function for annual flows is Pearson III, to transform the standardized data to normalized data Wilson-Hilferty transformation is used [1]. Later, these data are disaggregated into monthly flows using V-S matrix model [22]. As the generated data are still standardized and normalized they are transformed to the data that has Pearson III probability distribution using Wilson-Hilbert transformation and afterwards they are also converted from standardized data to ordinary stream flow data. The synthetic stream flow data are generated in 1000 sequences which each sequence is equal in length to historical data. Statistical characteristics of both historical and generated annual stream flow data are compared in Table 4. It is clear from this table that the performance of AR (1) model in preserving annual characteristics of stream flow is acceptable. The performance of V-S model in this sense is also satisfactory.

\subsection{Reservoir systems storage-yield-performance analysis}

The analysis of reservoir systems with performance indices is carried out using modified Sequent Peak Algorithm (SPA) [5], [24]. This algorithm is capable of undertaking both time based reliability and vulnerability in determining CP of reservoir systems [8], [6], [25]. The reservoir systems are simulated for 1000 sequences of synthetic data. The analysis for every sequence is carried out assuming constant demands in all months of the year for $20 \%, 30 \%, 40 \%$, 
$50 \%, 60 \%, 70 \%$, and $80 \%$ of Mean Annual Flow (MAF). The combination of time based reliabilities of 90\%, 93\%, $95 \%, 96 \%, 97 \%, 98 \%, 99 \%$ and $100 \%$ and the vulnerabilities of $0 \%, 5 \%, 10 \%, 15 \%, 20 \%, 25 \%$ and $30 \%$ are also undertaken in the simulation. Finally $\mathrm{CP}$ is calculated for each site with different combinations of demand, reliability and vulnerability by modified SPA.

Table 4: Comparison between Statistical Characteristics of Historical and Generated Synthetic Annual Stream flow Data in Study Sites

\begin{tabular}{ccccccc}
\hline \multirow{2}{*}{ Site } & Data & $\begin{array}{c}\text { Mean } \\
\left(\times 10^{6} \mathrm{~m}^{3}\right)\end{array}$ & $\begin{array}{c}\text { SD } \\
\left(\times 10^{6} \mathrm{~m}^{3}\right)\end{array}$ & CV & Skew & $\begin{array}{c}\text { Serial correlation } \\
(\text { lag-1) }\end{array}$ \\
\hline \multirow{2}{*}{ Melaka } & Historical & 185.75 & 73.54 & 0.396 & 0.478 & 0.160 \\
& Generated & 185.17 & 71.77 & 0.388 & 0.448 & 0.104 \\
\multirow{2}{*}{ Muar } & Historical & 1359.00 & 656.23 & 0.483 & 2.026 & 0.175 \\
& Generated & 1351.84 & 619.29 & 0.458 & 1.861 & 0.125 \\
\hline
\end{tabular}

\section{Results and discussion}

\subsection{Within-year and over-year behavior}

Figure 2 shows the relationship between $\mathrm{CP}$ and parameter $\mathrm{m}$ for different time-based reliabilities in $30 \%$ vulnerability for both rivers. Each curve in Figure 2 includes 7 different demands of 20\%, 30\%, 40\%, 50\%, 60\%, 70\% and 80\% of mean annual flows (MAF). Figure 2 depicts that for $100 \%$ time-based reliability, the transition between within-year and over-year behavior ( $\mathrm{CP}=1$ year) occurs at approximately $\mathrm{m}=1.8$ for Melaka river and $\mathrm{m}=1.1$ for Muar river. It is also noted that the magnitude of transitional $\mathrm{m}$ also depends upon time based reliability. For instance, at $90 \%$ reliability in Melaka River the transitional $\mathrm{m}$ is about 1.3. On contrary, parameter $\mathrm{m}$ method determines $\mathrm{m}=1$ as a transitional criteria between within-year and over-year behaviors [17]. Consequently parameter $\mathrm{m}$ approach is an approximate method and may not be complete and the real magnitude of transitional $\mathrm{m}$ depends upon other parameters such as reliability, vulnerability and length of data. Therefore later, parameter $\mathrm{m}$ method was modified by including $\mathrm{C}_{\mathrm{V}}$ of annual flows so over-year systems will have $\mathrm{CV}>1$ (or $\mathrm{CV}<1$ and $0 \leq \mathrm{m} \leq \mathrm{CV}$ ) and within-year systems will have $\mathrm{CV}<1$ and $\mathrm{m}$ satisfying the inequality $\mathrm{CV} \leq \mathrm{m} \leq 1 / \mathrm{CV}$ [18]. However Figure 2 indicates that there are some cases which $\mathrm{CV}<1$ for both rivers and $\mathrm{CV} \leq \mathrm{m} \leq 1 / \mathrm{CV}(0.388 \leq \mathrm{m} \leq 2.577$ for Melaka River and $0.458 \leq \mathrm{m} \leq 2.183$ for Muar River) which means reservoir should experience within-year behavior according to modified parameter $\mathrm{m}$ method. However the behavior of reservoir according to the Monte Carlo simulation results is over-year. For instance in Figure 2, for Melaka all the behavior cases are predicted as within-year by modified parameter m method, however in reality the majority of the cases have over-year behavior so the modified parameter m method may be even less efficient than the original parameter $m$ method in distinguishing between two different types of reservoir behaviors.
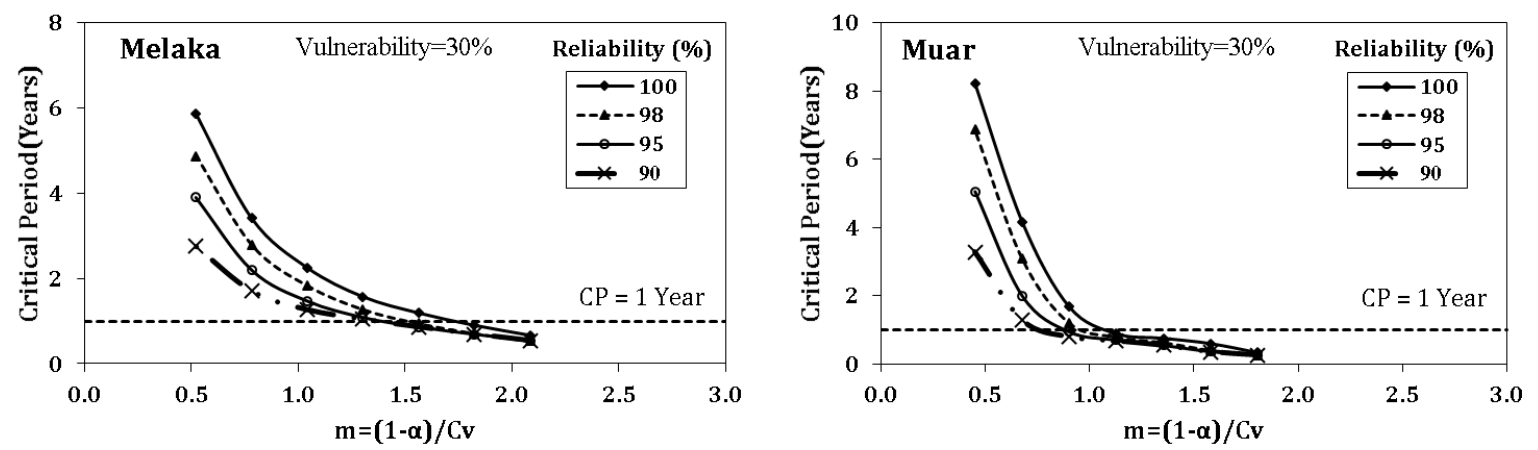

Fig. 2: Relationship between CP and M Parameter for Vulnerability $=30 \%$ and Different Reliabilities in Melaka and Muar Rivers

Consequently, the only reasonable approach to predict the behavior of reservoir systems is to modeling $\mathrm{CP}$ using regression equations involving effective parameters such as reliability and vulnerability. Hence in this study appropriate equations are developed for each site separately to predict $\mathrm{CP}$.

\subsection{Modeling the critical period of reservoir systems}

\subsubsection{The function of $\mathrm{CP}$ and parameter $\mathrm{m}$}

It is perceived from Figure 2 that the relationship between $\mathrm{CP}$ and parameter $\mathrm{m}$ may have a power form. In this study to find the fittest type of relationship trial and error method is employed in the way that some kinds of relationships such as linear, power, logarithmic and exponential are fitted to the analysis results and the one with the highest $\mathrm{R}^{2}$ - 
coefficient is selected. It is observed that for both Melaka and Muar rivers the fittest equation between CP and $\mathrm{m}$ has a power form. Therefore, the equation between $\mathrm{CP}$ and parameter $\mathrm{m}$ can be suggested as follows:

$\mathrm{CP}=\mathrm{A} \cdot \mathrm{m}^{\mathrm{B}}$

This equation includes 7 demands consists of 20\%, 30\%, 40\%, 50\%, 60\%, 70\% and 80\% of mean annual flows (MAF). $\mathrm{CP}$ is critical period measured in years. The parameters A and B depend upon site characteristics, Reliability and Vulnerability indices. The coefficients of $\mathrm{A}$ and $\mathrm{B}$ together with their $\mathrm{R}^{2}$ - coefficients for different reliabilities and vulnerabilities are presented at Table 5. It is obvious from this table that Equation (4) has a very good fitness with simulation results because of closeness of $\mathrm{R}^{2}$ coefficients to one in all the cases which makes it appropriate to modeling CP.

Table 5: Coefficients of A and B Together with their $\mathrm{R}^{2}$-Coefficients for Different Reliabilities and Vulnerabilities for Both Sites.

\begin{tabular}{|c|c|c|c|c|c|c|c|c|c|c|c|c|c|c|}
\hline \multicolumn{2}{|c|}{ Site } & \multicolumn{3}{|c|}{ Melaka } & \multicolumn{3}{|c|}{ Muar } & \multicolumn{4}{|c|}{ Melaka } & \multicolumn{3}{|c|}{ Muar } \\
\hline Rel. & Vul. $^{* * *}$ & A & $\mathrm{B}$ & $\mathrm{R}^{2}$ & A & B & $\mathrm{R}^{2}$ & Vul. & $\mathrm{A}$ & B & $\mathrm{R}^{2}$ & A & $\mathrm{B}$ & $\mathrm{R}^{2}$ \\
\hline 1.00 & 0.00 & 2.28 & -1.55 & 0.99 & 1.42 & -2.28 & 0.98 & 0.00 & 2.28 & -1.55 & 0.99 & 1.42 & -2.28 & 0.98 \\
\hline 0.99 & & 2.23 & -1.55 & 0.99 & 1.39 & -2.30 & 0.98 & & 2.10 & -1.57 & 0.99 & 1.27 & -2.34 & 0.99 \\
\hline 0.98 & & 2.21 & -1.55 & 0.99 & 1.36 & -2.29 & 0.98 & & 2.00 & -1.56 & 1.00 & 1.20 & -2.32 & 0.99 \\
\hline 0.97 & & 2.19 & -1.54 & 1.00 & 1.34 & -2.27 & 0.98 & & 1.91 & -1.52 & 1.00 & 1.13 & -2.26 & 0.99 \\
\hline 0.96 & 0.05 & 2.17 & -1.54 & 1.00 & 1.32 & -2.26 & 0.98 & 0.20 & 1.85 & -1.49 & 1.00 & 1.08 & -2.19 & 0.99 \\
\hline 0.95 & & 2.14 & -1.51 & 1.00 & 1.32 & -2.24 & 0.98 & & 1.79 & -1.44 & 1.00 & 1.06 & -2.14 & 0.99 \\
\hline 0.93 & & 2.11 & -1.49 & 1.00 & 1.29 & -2.22 & 0.98 & & 1.68 & -1.35 & 1.00 & 0.99 & -2.00 & 0.98 \\
\hline 0.90 & & 2.07 & -1.46 & 0.99 & 1.27 & -2.18 & 0.98 & & 1.58 & -1.24 & 0.99 & 0.92 & -1.85 & 0.97 \\
\hline 0.99 & & 2.19 & -1.55 & 0.99 & 1.35 & -2.32 & 0.98 & & 2.05 & -1.58 & 0.99 & 1.24 & -2.36 & 0.99 \\
\hline 0.98 & & 2.14 & -1.55 & 0.99 & 1.31 & -2.30 & 0.99 & & 1.91 & -1.56 & 1.00 & 1.15 & -2.32 & 0.99 \\
\hline 0.97 & & 2.10 & -1.54 & 1.00 & 1.27 & -2.28 & 0.98 & & 1.83 & -1.53 & 1.00 & 1.07 & -2.26 & 0.99 \\
\hline 0.96 & 0.10 & 2.06 & -1.52 & 1.00 & 1.24 & -2.25 & 0.98 & 0.25 & 1.75 & -1.48 & 1.00 & 1.01 & -2.17 & 0.99 \\
\hline 0.95 & & 2.00 & -1.48 & 1.00 & 1.22 & -2.21 & 0.98 & & 1.66 & -1.40 & 1.00 & 0.98 & -2.11 & 0.99 \\
\hline 0.93 & & 1.95 & -1.45 & 1.00 & 1.18 & -2.16 & 0.97 & & 1.55 & -1.30 & 1.00 & 0.91 & -1.96 & 0.98 \\
\hline 0.90 & & 1.89 & -1.39 & 1.00 & 1.14 & -2.08 & 0.97 & & 1.45 & -1.17 & 0.99 & 0.84 & -1.76 & 0.97 \\
\hline 0.99 & & 2.14 & -1.56 & 0.99 & 1.32 & -2.33 & 0.99 & & 2.01 & -1.60 & 0.99 & 1.21 & -2.36 & 0.99 \\
\hline 0.98 & & 2.07 & -1.55 & 1.00 & 1.25 & -2.31 & 0.99 & & 1.85 & -1.57 & 1.00 & 1.10 & -2.33 & 0.99 \\
\hline 0.97 & & 2.00 & -1.52 & 1.00 & 1.20 & -2.27 & 0.99 & & 1.74 & -1.52 & 1.00 & 1.02 & -2.25 & 0.99 \\
\hline 0.96 & 0.15 & 1.95 & -1.50 & 1.00 & 1.16 & -2.22 & 0.98 & 0.30 & 1.64 & -1.46 & 1.00 & 0.95 & -2.16 & 0.99 \\
\hline 0.95 & & 1.89 & -1.47 & 1.00 & 1.13 & -2.20 & 0.98 & & 1.57 & -1.40 & 1.00 & 0.91 & -2.07 & 0.99 \\
\hline 0.93 & & 1.81 & -1.40 & 1.00 & 1.07 & -2.08 & 0.97 & & 1.45 & -1.27 & 1.00 & 0.84 & -1.91 & 0.99 \\
\hline 0.90 & & 1.73 & -1.32 & 1.00 & 1.02 & -1.96 & 0.97 & & 1.33 & -1.12 & 0.99 & 0.77 & -1.69 & 0.98 \\
\hline
\end{tabular}

* Reliability **Vulnerability

\subsubsection{Regression equations to estimate Critical Period}

To develop regression equations to predict $\mathrm{CP}$ it is required to express coefficients of $\mathrm{A}$ and $\mathrm{B}$ in Equation (4) as a function of reliability and vulnerability indices. The A and B coefficients can be expressed as follow:

$A=a_{1}+b_{1} \cdot R_{e}+c_{1} \cdot V_{u}$

$\mathrm{B}=\mathrm{a}_{2}+\mathrm{b}_{2} \cdot \mathrm{R}_{\mathrm{e}}+\mathrm{c}_{2} \cdot \mathrm{V}_{\mathrm{u}}$

Where $R_{e}$ is the reliability indices between 0.90 and 1.00 and $V_{u}$ is vulnerability indices between 0.00 and 0.30 .

The coefficients of $a_{1}, b_{1}, c_{1}, a_{2}, b_{2}$ and $c_{2}$ can be obtained through multiple regression analysis by employing the least squares method for each two sites separately using coefficients of A and B corresponding to different reliabilities and vulnerabilities that is presented in Table 5. Each of these equations is calibrated for 48 cases for both rivers separately $(8$ (reliabilities) $\times 6$ (vulnerabilities)). The estimated coefficients and t-statistics are presented in Table 6 . The t-statistics involves $\mathrm{t}$-values and critical $\mathrm{t}$-value. The $\mathrm{t}$-values are obtained through dividing the estimated coefficient by their corresponding standard errors. The t-values show the significance of corresponding coefficients in regression analysis and their absolute values should be greater than critical t-value to be statistically effective in regression analysis. Critical t-value can be obtained by specified degree of freedom (DF) of regression analysis and assuming probability level $(\alpha)=0.05$ or 0.10 through a table in a statistical manual. In this analysis $\mathrm{DF}=45$ and $\alpha=0.10$ and the critical $\mathrm{t}-$ value is 1.68. It can be seen that absolute value of all t-values in Table 6 are greater than critical t-value (1.68) which implies that all variables are significant in the regression analysis. 
Table 6: Estimated Regression Coefficients and T-Statistics

\begin{tabular}{|c|c|c|c|c|c|c|c|c|}
\hline \multirow{2}{*}{ Site } & \multirow{2}{*}{ Coef. } & \multicolumn{3}{|c|}{ A } & \multirow{2}{*}{ Coef. } & \multicolumn{3}{|c|}{$\mathrm{B}$} \\
\hline & & Estimate & t-value & Critical t-value & & Estimate & t-value & Critical t-value \\
\hline \multirow{3}{*}{ Melaka } & $a_{1}$ & -1.74 & -4.61 & 1.68 & $a_{2}$ & 1.20 & 4.40 & 1.68 \\
\hline & $b_{1}$ & 4.11 & 10.61 & 1.68 & $\mathrm{~b}_{2}$ & -2.82 & -10.07 & 1.68 \\
\hline & $\mathrm{c}_{1}$ & -1.70 & -14.04 & 1.68 & $\mathrm{c}_{2}$ & 0.18 & 2.02 & 1.68 \\
\hline \multirow{3}{*}{ Muar } & $a_{1}$ & -1.35 & -5.50 & 1.68 & $\mathrm{a}_{2}$ & 1.56 & 3.86 & 1.68 \\
\hline & $b_{1}$ & 2.83 & 11.24 & 1.68 & $\mathrm{~b}_{2}$ & -3.95 & -9.50 & 1.68 \\
\hline & $\mathrm{c}_{1}$ & -1.25 & -15.85 & 1.68 & $\mathrm{c}_{2}$ & 0.23 & 1.78 & 1.68 \\
\hline
\end{tabular}

Summary statistics of regression analysis is presented in Table 7. The $\mathrm{R}^{2}$ is the coefficient of determination of regression analysis which is acceptable for all the cases in the analysis. SEE is standard error estimate of A and B. FStat is F statistics or F value which is high enough in all cases. Degree of freedom of regression analysis is shown by DF which is 45 for all the cases and finally F-dist. is the probability that a higher value of F-stat occurred by chance and as it is seen, F-dist. values are 0.00 for all the cases in the analysis which implies that the high magnitude of F-stat is not occurred by chance and are valid. Consequently according to Table 6 and Table 7 it is concluded that the regression analysis is statistically efficient enough to estimate both A and B coefficients in the study sites.

\subsubsection{Performance of equation to estimate critical period}

Having executed the regression analysis, calibrating the CP equations and checking the efficiency of the analysis statistically, it is pertinent to evaluate the performance of these equations in predicting $\mathrm{CP}$. The evaluation is performed by the comparison between predicted and observed results of reservoir simulation. The CP equations for Melaka and Muar are as follow:

$$
\begin{aligned}
& \mathrm{CP}(\text { Melaka })=\left(-1.74+4.11 \mathrm{R}_{\mathrm{e}}-1.70 \mathrm{~V}_{\mathrm{u}}\right) \mathrm{m}^{\left(1.20-2.82 \mathrm{R}_{\mathrm{e}}+0.18 \mathrm{~V}_{\mathrm{u}}\right)} \\
& \mathrm{CP}(\text { Muar })=\left(-1.35+2.83 \mathrm{R}_{\mathrm{e}}-1.25 \mathrm{~V}_{\mathrm{u}}\right) \mathrm{m}^{\left(1.56-3.95 \mathrm{R}_{\mathrm{e}}+0.23 \mathrm{~V}_{\mathrm{u}}\right)}
\end{aligned}
$$

Where, CP is the critical period in years, $R_{e}$ is time-based reliability indices between 0.90 and 1.00 and $V_{u}$ is vulnerability indices between 0.00 and 0.30 .

Table 7: Summary Statistics of Regression Analysis

\begin{tabular}{ccccc}
\hline Site & \multicolumn{2}{c}{ Melaka } & Muar & A \\
\hline & A & B & 0.92 & 0.71 \\
R & 0.91 & 0.74 & 0.05 & 0.09 \\
SEE & 0.08 & 0.06 & 261.8 & 56.3 \\
F-stat & 215.6 & 63.8 & 45 & 45 \\
DF & 45 & 45 & 0.00 & 0.00 \\
F-dist. & 0.00 & 0.00 & & \\
\hline
\end{tabular}

The performance of Equations (7) and (8) are shown in Figure 3. The simulation of critical period is executed for each site to consists of 336 cases $(8$ (reliabilities $) \times 6$ (vulnerabilities $) \times 7$ (demands) $)$ where each case represents a point plotted in Figure 3. It is observed that for both sites the points are located around $y=x$ line which means that the observed results from simulation are accurately reproduced by the estimated results from regression equations even when $\mathrm{CP}$ is less than one year and the reservoir behavior is within year. This is encouraging because there are currently a few relationships to predict CP for within-year behavior. The correlation coefficient between observed CPs and estimated CPs are 0.9939 and 0.9867 for Melaka and Muar rivers, respectively and also the standard error in evaluating CPs are 0.1686 and 0.3667 for two sites, respectively which generally show the regression equations to predict CP perform very well. 


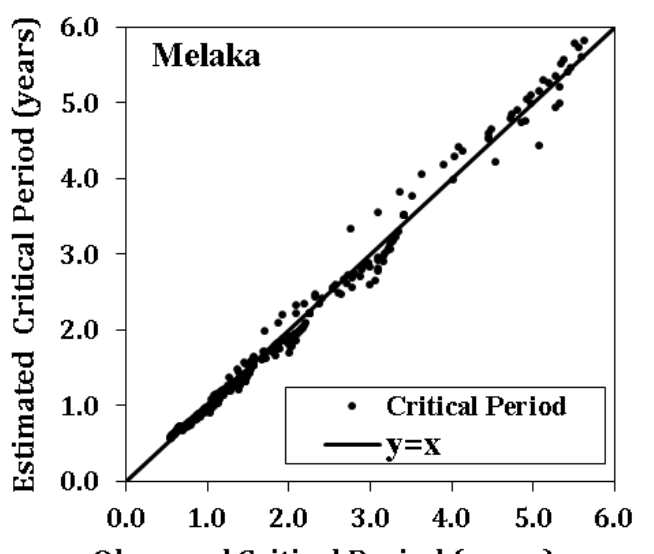

Observed Critical Period (years)

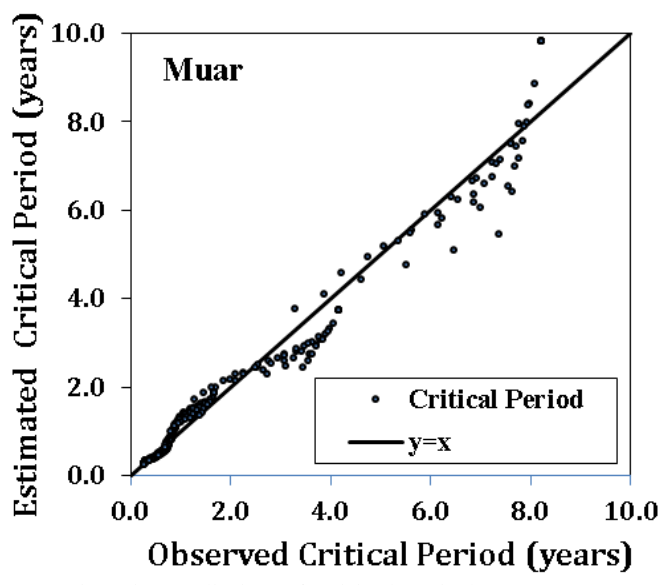

Observed Critical Period (years)

Fig. 3: Performance of Developed Regression Equations in Prediction of Critical Period

\section{Conclusions}

Reservoir has to be analyzed using Monte Carlo Simulation approach in order for the results to be realistic and to consider droughts that are more severe than historical ones and may occur in future. Moreover, it is necessary to use performance indices such as reliability and vulnerability in reservoir analysis to economize the planning of reservoir systems and also to control the performance of reservoirs during failure periods.

Developing regression equations to predict $\mathrm{CP}$ is a powerful tool to determine the behavior of reservoirs systems and to identify the aggregation level of the data that should be employed in designing stage of reservoirs.

The main specific outcomes of this study are as follow:

1) Combination of $\mathrm{AR}(1)$ and V-S data generation models under Pearson III probability distribution function for both monthly and annual stream flow data in Melaka and Muar are efficient enough to preserve historical data characteristics such as mean, standard deviation, skewness and auto-correlation lag one.

2) Within-year and over-year behavior of reservoirs in Melaka and Muar rivers may not be identified by parameter $\mathrm{m}$ or modified parameter $\mathrm{m}$ methods even when the reliability is $100 \%$. Therefore, to determine the real behavior of reservoir systems it is necessary to develop regression equations to predict $\mathrm{CP}$.

3) $\mathrm{CP}$ of reservoir systems is not only dependent upon draft and variation of stream flow but also it is influenced by other parameters such as performance indices (reliability and vulnerability).

4) Regression equations are developed to predict the CP of reservoir systems in Melaka and Muar rivers separately. The performance of these equations are very good even when $\mathrm{CP}<1$ year. This is encouraging because there are currently a few relationships that can predict $\mathrm{CP}$ of within-year behavior.

5) The CP equations are developed for Melaka and Muar rivers separately because these two sites are different and developing single CP equation for these two sites may decrease the accuracy. However these equations can be used for any sites in Malaysia provided that their key annual stream flow characteristics particularly CV and skewness are close to Melaka and Muar.

6) The task of developing CP prediction equations in Malaysia has begun with this study and there is potential and necessity to develop CP equations for other sites in Malaysia separately. Moreover as an extension to this study it is also recommended to develop $\mathrm{CP}$ equations and to generalize this equation for different hydrologic regions in Malaysia.

\section{Acknowledgment}

The authors would like to acknowledge University Sains Malaysia for funding this research through RUI grant (1001/PAWAM/814194) and also would like to thank Department of Irrigation and Drainage Malaysia (DID) for providing the stream flow data of study sites.

\section{References}

[1] D. P. Loucks, J. R. Stedinger \& D. A. Haith, "Water Resources System Planning and Analysis," Prentice-Hill, Englewood Cliffs, New Jersey, USA, 1981

[2] J. R. Stedinger \& M. R. Taylor, "Synthetic stream flows generation. 2. Effect of parameter uncertainty," Water Resources Research, 18 (4), 919-924, 1982

[3] H. N. Phien, "Reservoir storage capacity with gamma inflows," Journal of Hydrology, 146, 383-389, 1993.

[4] A. T. Silva \& M. M. Portela, "Disaggregation modeling of monthly stream flows using a new approach of the method of fragments," Hydrological Sciences Journal, 57(5), 2012.

[5] S. M. Lele, "Improved algorithms for reservoir capacity calculation incorporating storage-dependent losses and reliability norm," Water Resour. Res. 23 (10), 1819-1823, 1987. 
[6] D. P. Loucks, "Quantifying trends in system sustainability,” Hydrol. Sci. J. 42 (4), 513-530, 1998.

[7] A. J. Adeloye \& N.R. Nawaz, "The inherent time-based reliability of storage-yield estimates for some reservoir sites in Yorkshire," Yorkshire Water Services Ltd., Halifax Road, Bradford, England, 1997.

[8] T. Hashimoto, J. R. Stedinger \& D. P. Louck, "Reliability, resiliency and vulnerability criteria for water resource system performance evaluation," Water Resources Research, 18(1), 14-20, 1982.

[9] A. J. Adeloye, M. Montaseri \& C. Garmann, "Curing the misbehavior of reservoir capacity statistics by controlling shortfall during failures using the modified sequent peak algorithm," Water Resources Research, 37(1), 73-82, 2001.

[10] B. W. Gould, "Statistical methods for estimating the design capacity of dams," J. Institut. Eng., Australia, 33(12), 405-416, 1916.

[11] P. A. P. Moran, "A probability theory of dams and storage systems," Australian Jour. Applied Science, 5, 116-124, 1954.

[12] R. A. Wurbs, "Reservoir system simulation and optimisation models," Journal of Water Resources Planning and Management, American Society of Civil Engineers, 119(4), 455-472, 1993.

[13] T. A. McMahon \& A. J. Adeloye, "Water Resources Yield," Water Resources Publications, LLC, USA, 2005.

[14] United States Corps of Engineers, "Hydrologic engineering methods for water resources development," Vol. 8 Reservoir Yield. Hydrologic Engineering Center, Davis, California, 1975.

[15] T. A. McMahon \& R. G. Mein, "River and Reservoir Yield," Water Resources Publications, Col., USA, 1986.

[16] M. Montaseri \& A. J. Adeloye, "Critical period of reservoir systems for planning purposes,” Journal of Hydrology, 224,115-136, 1999.

[17] R. M. Vogel \& J.R. Stedinger, “Generalised storage-reliability-yield relationships,” Journal of Hydrology, 89, 303-327, 1987.

[18] R. M. Vogel, M. Lane, R.S. Ravindrian and P. Kirshen, "Storage reservoir behavior in the United States," Journal of Water Resources Planning and Management, American Society of Civil Engineers, 125(5), 245-254, 1999.

[19] N. T. Kottegoda, "Stochastic water resources technology," The Macmillan Press Ltd, 1980.

[20] J. D. Salas, "Analysis and Modeling of hydrologic time series in Hand book of hydrology," Edited by D. R. Maidment, McGraw- Hill book Co., New York, 1993.

[21] R. M. Vogel, "The Probability Plot Correlation Coefficient Test for the Normal, Lognormal, and Gumbel Distributional Hypotheses," Water Resources Research, 22(4), 587-590, 1986.

[22] D. Valencia \& J.C. Schaake, "Disaggregation process in stochastic hydrology," Water Resources Research, 9(3), 580-585, 1973.

[23] H. A. Thomas \& M. B. Fiering, "Mathematical synthesis of stream flows sequences for the analysis of river basins by simulation," In: Maass (Ed.). Design of Water Resource Systems, Harvard University Press, Cambridge, MA, chap. 12, 1962.

[24] A. J. Adeloye \& M. Montaseri, "Adaptation of a single reservoir technique for multiple reservoir storage-yield-reliability analysis," In: Zebidi, H. (Ed.). Water: A Looming Crisis, Proceedings of the International Conference on World Water Resources at the Beginning of the 21 st Century, UNESCO, Paris, pp. 349-355, 1998.

[25] X. Zxongue, K. Jinno, A. Kawanura, S. Takesaki \& K. Ito, "Performance risk analysis for Fukuoka water supply system," Water Resources Management, 12, 13-30, 1998. 